\title{
Subpopulations at increased risk of adverse health outcomes from air pollution
}

\author{
I. Annesi-Maesano*, N. Agabiti" ${ }^{\#}$ R. Pistelli", M-F. Couilliot*,+, F. Forastiere
}

Subpopulations at increased risk of adverse health outcomes from air pollution. I. Annesi-Maesano, N. Agabiti, R. Pistelli, M-F. Couilliot, F. Forastiere. (C)ERS Journals Ltd 2003.

ABSTRACT: Epidemiological research to identify subpopulations with enhanced susceptibility to air pollution is still at an early stage.

From the available studies, there is evidence that both "endogenous" and "exogenous" factors contribute to individual susceptibility. Females and the elderly are at an increased risk of pollution-related diseases. Moreover, some chronic clinical conditions seem to be good candidates for identifying the "frail" populations: chronic obstructive pulmonary disease including asthma, coronary heart diseases, congestive heart failure, and heart rhythm disorders.

It seems clear that epidemiological research on susceptibility in the future should investigate the underlying biological and physiological mechanisms, in addition to the environmental and toxicological effects.

Eur Respir J 2003; 21: Suppl. 40, 57s-63s.
*Dept of Epidemiology of Immediate Hypersensitivity, INSERM U472: Epidemiology and Biostatistics, Villejuif, France, ${ }^{\#}$ Dept of Epidemiology ASL RME, Lazio Region, Rome, Italy, Dept of Clinical Medicine, Catholic University, Rome, Italy, ${ }^{+}$Dept of Public Health, School of Medicine Paris XIII, Bobigny, France.

Correspondence: I. Annesi-Maesano, Dept of Epidemiology of Immediate Hypersensitivity, INSERM U472: Epidemiology and Biostatistics, 16, Ave PV-Couturier, F94807 Villejuif, France. Fax: 33145595169

E-mail: annesi@vjf.inserm.fr

Keywords: Air pollution, elderly, gender, respiratory diseases, sex, susceptibility

Received and accepted: April 122002
There is increasing evidence that the effect of air toxicants varies from one individual to another because of the variation in the susceptibility level, i.e. the degree of vulnerability, frailty or sensitivity of the individual to exposures, stimuli, and influences. Susceptibility results from the complex interrelationships of various mechanisms. It has been suggested that those who suffer more from exposure to air pollution levels are likely to be individuals, mainly females and/or elderly people, already at risk because of serious cardiovascular or pulmonary diseases $[1,2]$. Few studies, however, have addressed the question of which specific subpopulations are most sensitive to air pollutants.

In the present paper, the authors will disentangle the complex mechanisms underlying individual susceptibility by investigating the features that predispose individuals to having a greater risk from air pollution. Although partial, this approach seems necessary to better comprehend the phenomenon of individual susceptibility. The paper will briefly present the epidemiological evidence regarding the link between air pollution and 1) sex/"gender", 2) certain clinical conditions, and finally, 3) various other characteristics on which specific hypotheses have been raised. This link will be discussed in the light of the suggested potential biological and physiological mechanisms by which air pollution may cause health effects, with a particular attention to those factors acting on individual susceptibility.

\section{Epidemiological studies on susceptibility to air pollution}

The issue of sensitivity to air pollution in epidemiological terms is a matter of effect modification; the level of response of a particular individual to a given level of air pollution, and his/her risk of morbidity or mortality are a function of biological, clinical and social factors (fig. 1). The search for such factors is obviously a research priority, but so far, only a few steps have been undertaken. Appropriate designs are needed to investigate susceptibility. The available time series studies on the acute health effects of air pollution cannot provide detailed descriptions of the populations affected, chiefly because they use routinely collected data (death certificates or hospital admissions). In a time series analysis, the clinical conditions, circumstances and characteristics of those affected (e.g. biological and physiological parameters) are usually not studied. Similarly, studies on long-term effects of air pollution considering individual susceptibility have been scanty so far. Some recent investigations, however, have used novel study designs and/or new approaches to evaluate shortterm as well as long-term effects of air pollution among specific population subgroups.

\section{Sex and "gender"}

Epidemiological data have shown that there are sex/ "gender" differences in the susceptibility to the action of air pollution. The effects seem to vary according to the type of pollutant in both children and adults. Young females are at higher risk than young males for an increased rate of respiratory symptoms, a diminished level of lung function and a greater asthma medication use due to air pollution (table 1). Furthermore, young female asthmatics have a higher risk of air pollution effects than young female nonasthmatics. All major pollutants are involved (table 1). However, only one study had a longitudinal design with the assessment of individual exposure.

Females also generally have a greater risk compared to males, although some studies did not find sex differences (table 2). Many studies, however, did not consider sex 


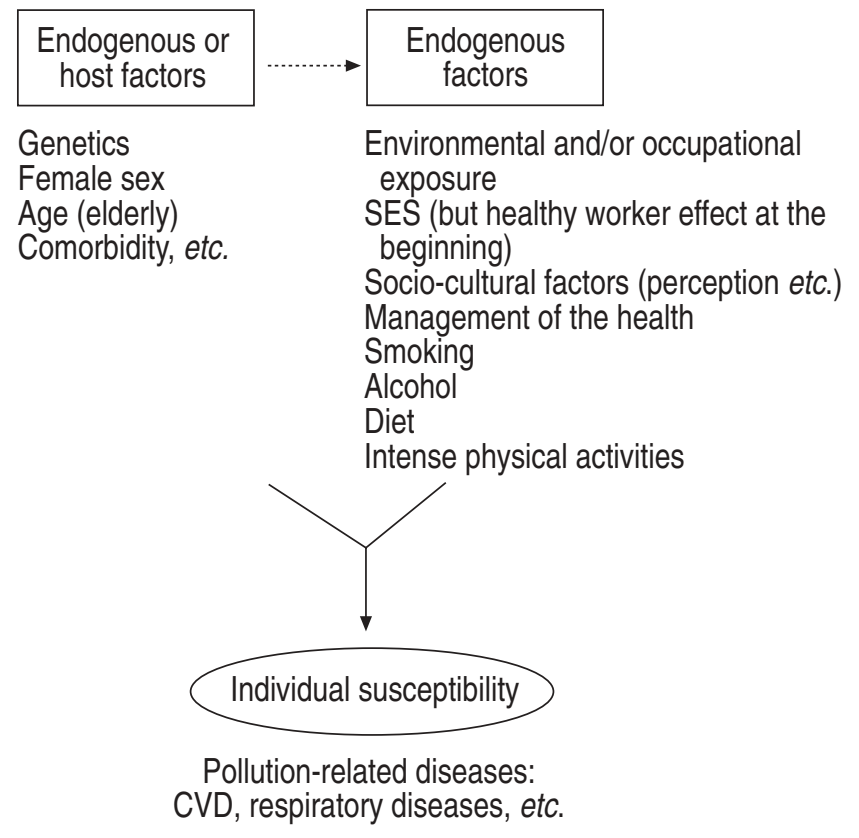

Fig. 1.- Potential risk factors for individual susceptibility to pollutionrelated diseases. SES: socioeconomic status; CVD: cardiovascular disease.

differences to a great extent. The three large cohort studies on long-term effects of air pollution, conducted in the USA, have examined the relationship between various particle indicators and mortality. Due to the prospective design, these studies are the most appropriate to investigate the causal relationship. There was no significant difference between males and females for all-cause mortality in the Six Cities Study [25], in the American Cancer Society (ACS) study [23] and in the Seventh-day Aventists Health Study on Smog (AHSMOG) [24]. However, males had a higher risk of respiratory cancer in the AHSMOG study and females of cardiopulmonary diseases in the ACS study.

Thus, available data have been based only on the comparison between males and females, which is reductive. More sophisticated designs are needed to study the differences between females and males. Objective assessments of biological (e.g. hormones, enzymes markers of inflammation) and physiological (e.g. lung function, bronchial hyperresponsiveness) parameters should be included. Furthermore, objective assessments of individual exposure to and internal dose of air pollution, which have rarely been performed so far, have to be undertaken.

Mechanisms. Differences in the susceptibility to air pollution observed between females and males are the result of the interaction of sex (genetic and biological) and "gender" (sociocultural) factors.

There are recognised sex differences in organ growth and development as well as in the maturation of the immune system. Females have smaller lung and airways calibre, a higher level of bronchial hyperresponsiveness, but suffer less than males from childhood respiratory infections. The heart of a female, relative to her body size, is also smaller (about two-thirds) and typically pulses at a higher rate than a male's. Sex differences generated by genetic and biological factors are responsible, through the production of hormones and enzymes, for the physiological variations observed between females and males. Unfortunately, the role of genetic factors has not yet been studied.

However, an interest in the sex hormones has begun in this

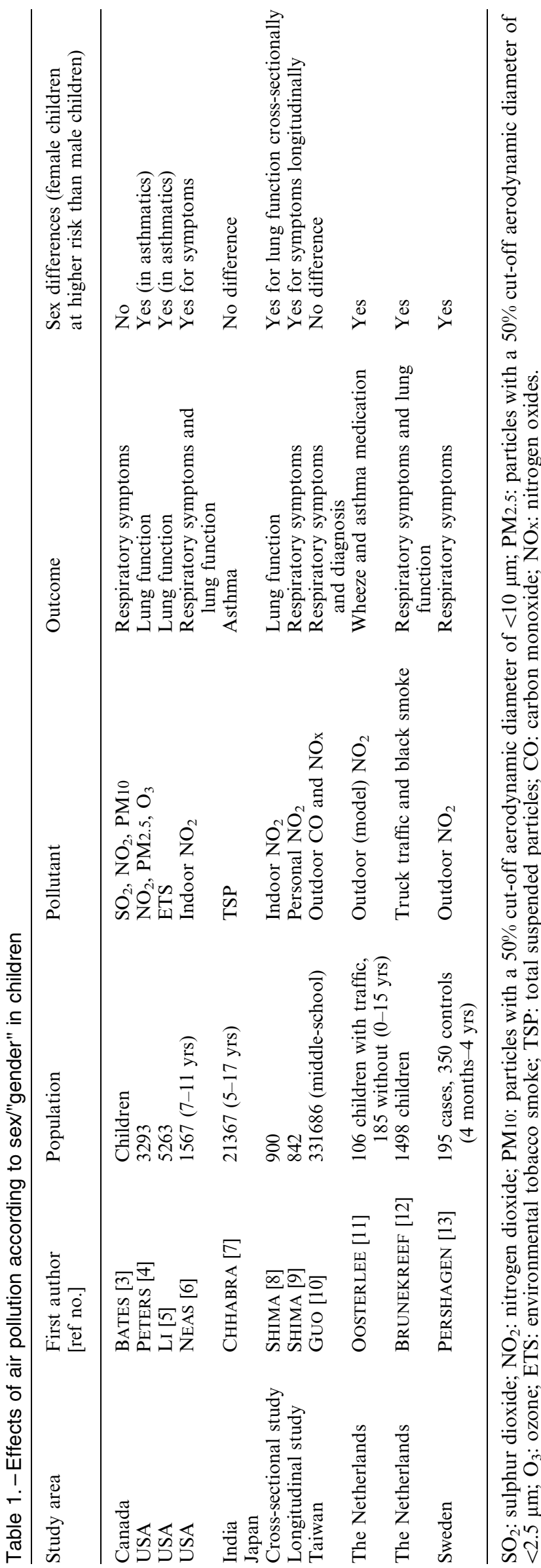




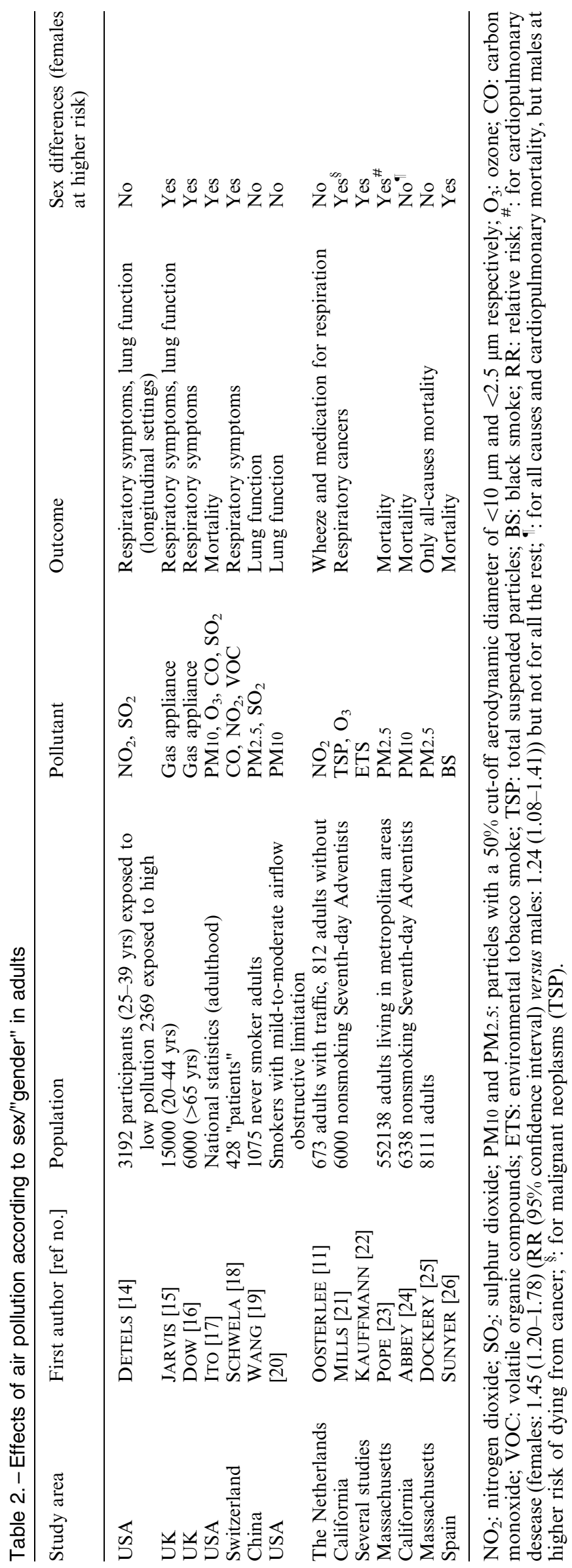

last decade, although there are still few population-based data. The most compelling evidence that sex hormones are involved emerges from natural models, i.e. menarche, menstrual cycle, contraception, pregnancy and menopause. In these models, clinical and functional variations can be measured in parallel with well-known fluctuations of the hormonal profile. Although oestrogen has a beneficial impact, which extends beyond sex and reproduction to virtually every part of a female's body (e.g. strengthening bones, fostering the growth of brain cells, blocking platelets that can clog arteries, altering insulin metabolism), it may contribute to a host of medical problems. Oestrogen might act on both the lung/airways and heart. Oestrogen is likely to exert an effect on the constriction of bronchial smooth muscle. Thus, oestrogen may contribute to the rise of asthma incidence in females in adolescence.

Fluctuations in oestrogen during the menstrual cycle may also cause flare-ups in asthma. In the late luteal or premenstrual phase (the 6 days before menstrual bleeding begins), when the corpus luteum disintegrates and oestrogen and progesterone levels begin to fall, some women may experience asthma [27]. The effect of the contraceptive pill on the lung can only be hypothesised, but clinical and functional improvement of asthma has been observed after normalisation of the hormonal profile in females.

Regarding pregnancy, it is known that this depends on the type of asthma phenotype. In most asthmatic females, pregnancy is characterised by amelioration of both clinical and functional indices of asthma. Furthermore, asthma attacks in the last period of the pregnancy and during labour are rare in these same females. This might be due to an increased production of progesterone and cortisol, which may exert a protective effect. However, females with severe asthma may present severe exacerbation of the disease, which has not yet been explained.

Finally, it has been shown that menopause can increase either the risk of asthma or the severity of pre-existing asthma in predisposed females. This might be due to an excess of estradiol in these predisposed females, which can enhance both the formation of prostaglandin and arachidonic acid metabolism implicated in asthma inflammation. Furthermore, during menopause, abnormally high levels of oestrogen, because of replacement therapy, can increase the risk of asthma [28], whereas physiologically low levels of oestrogens may have protective effects.

Abundant knowledge also exists in the case of the cardiovascular system. It is well known that, throughout the reproductive years, oestrogen prevents the build-up of atherosclerotic plaque in the arteries, boosts levels of the beneficial form of cholesterol (high-density lipoprotein (HDL)) and lowers heart-harming low-density lipoprotein (LDL), thus protecting females from cardiovascular disease (CVD). However, oral contraceptives, even those with lower oestrogen, raise LDL and lower HDL, which increases CVD risk. As their oestrogen levels fall at midlife, the risk of CVD rises for all females. Like oral contraceptives, the menopause brings a rise in LDL and a small decline in HDL. This explains why the annual risk of CVD is reduced for every year a female continues menstruating.

Unfortunately, in spite of the incipient research on sexual differences in the development of diseases having raised hypotheses on the implicated mechanisms, the precise role played by air pollution on these mechanisms has not yet been examined.

"Gender" is responsible for differences in environmental exposures, which may be crucial in the case of air pollution. Due to sociocultural factors, personal habits and exposure vary between females and males throughout the world [22]. Because of differences in activities, occupational and domestic exposures differ between females and males. Females are more exposed than males to some hazards (e.g. nitrogen dioxide 
[15] and biomass smoke [29] due to cooking, passive smoking at home, hygiene/cosmetic products, indoor exposures, cleaning).

Similarly, "gender" differences exist in diet, which can have repercussions on obesity, related to both asthma and CVD.

However, there are also "gender" differences in perception, reporting and interpretation of risk and health outcomes [22]. It is not yet clear, for instance, whether the asthma exacerbations occurring in many females during the premenstrual period are due to objectively measurable intensification of the disease or to the increased perception of symptoms caused by the particular psychological state before menstruation [27].

Regarding health outcomes, there is also a difference between females and males in their management (e.g. diagnosis, treatment, emergency room visits). According to an analysis in the USA [30, 31], females were less likely than males to get clotdissolving drugs, to limit the damage of a heart attack, or to receive standard medication like aspirin or beta-blockers. This "gender" gap in treatment may be one reason why the death rate for CVD has declined only for males. Similar patterns have been seen in respiratory health.

Differences due to the interactions between sex and "gender" can also exist, but they are difficult to study [22]. They concern factors such as, childhood exposures, active smoking, nutrition and diet, exercise, occupational exposure, and air pollution exposure. For instance, diet, tobacco and alcohol consumption differ between females and males, not only because of sociocultural factors, and thus of exposure, but also because of differences in biological resistance.

An example of the complex interactions between sex and "gender" is provided in table 3. Subgroup analysis in a basedpopulation sample of 3,941 adolescents living in a semirural zone of France showed that undiagnosed exercise-induced asthma, as defined by a report of exercise-induced wheezing attacks in the past year in the absence of a physician's diagnosis of asthma (42 out of the 259 with exercise-induced asthma), was independently associated with being a young female, after controlling for potential confounders (table 3). This depends on sexual factors. Compared to young males, young females have a smaller airway calibre in absolute terms (forced expiratory volume in one second (FEV1)), but a higher ratio of airway calibre to lung volume (FEV1/vital capacity), which is partly responsible for their higher level of bronchial hyperresponsiveness. Also, "gender" factors influence the environmental exposures of young females as well as

Table 3.-Reported undiagnosed exercise-induced asthma (UEIA) according to sex/"gender" among 3,941 adolescents living in France (International Study of Asthma and Allergies in Childhood (ISAAC) Phase I - West Marne)

\begin{tabular}{lrrr}
\hline \multirow{2}{*}{ Factors } & \multicolumn{2}{c}{ UEIA } & \multirow{2}{*}{ OR $(95 \% \mathrm{CI})^{\#}$} \\
\cline { 2 - 3 } & No & Yes & \\
\hline Positively related \% & & & \\
$\quad$ Female sex & 38.4 & 56.1 & $2.05(1.50-2.81)^{* * * *}$ \\
$\quad$ Ever smoking & 49.7 & 63.4 & $1.75(1.28-2.39)^{* * *}$ \\
$\quad$ Peer's smoking & 39.5 & 50.6 & $1.57(1.14-2.15)^{* * *}$ \\
$\quad$ Owning a pet & 50.6 & 60.8 & $1.51(1.06-2.15)^{* * *}$ \\
$\quad$ Moulds at home & 17.0 & 26.0 & $1.72(1.16-2.55)^{* * *}$ \\
Negatively related \% & & & \\
$\quad$ Personal history of allergy & 65.6 & 49.2 & $0.51(0.37-0.70)^{* * * *}$ \\
$\quad$ Paternal asthma & 15.1 & 7.7 & $0.47(0.29-0.74)^{* * *}$ \\
$\quad$ Maternal asthma & 14.7 & 8.0 & $0.51(0.32-0.81)^{* *}$ \\
\hline
\end{tabular}

The sample included $52.2 \%$ of female adolescents. OR: odds ratio; CI: confidence interval. \#: using the logistic regression model taking all factors simultaneously into account. **: $\mathrm{p}<0.01 ; * * *: \mathrm{p}<0.001$. the way they have their diseases managed, fill in the questionnaires, and possibly practice sport.

Perspectives. Since information on the differences between females and males has been derived by studies as the result of a secondary analysis, further research on the differences between males and females could be improved by the following: 1) stratification rather than adjustment on sex in the analysis of the collected data; 2 ) taking into account comparable exposure between males and females; and 3) promoting the study of the biological differences between males and females overall when exposed to external aggressions like air pollution. A metaanalysis of existing data will be useful in this context.

\section{Clinical conditions}

Various chronic clinical conditions seem to be the best candidates to trace the true "frail" populations susceptible to the effects of air pollution: chronic obstructive pulmonary disease (COPD) including asthma, coronary heart diseases, heart failure, and disorders of the heart rhythm. There is obviously an extreme overlap between these conditions and, especially in the elderly; they all appear in combination as frequent causes of comorbidity.

SUNYER et al. [32] conducted the first study on factors possibly conferring susceptibility to the acute role of air pollution. By using a case-crossover analysis to evaluate mortality in a cohort of patients with COPD, these authors found that older females, patients admitted to intensive care units, and patients with a higher rate of emergency room visits were at greater risk of dying, in association with black smoke.

ZANOBETTI et al. [33] examined whether hospital admissions or secondary diagnoses for heart disease, COPD and pneumonia between 1985-1994 predisposed persons to a greater risk from air pollution. People with asthma, acute respiratory infections, and defects in the electrical control of the heart, conductive heart disorders or dysrhythmias emerged as risk groups for particulate matter effects, in terms of hospital admissions.

Using individual information on decedents of the Quebec Health Insurance Plan database (billing records on medical services, diagnoses coded by physicians, drug prescriptions), GOLDBERG et al. [34] found that daily mortality increased twice, as result of particle pollution among persons who had had acute lower respiratory diseases, chronic coronary artery diseases (especially acute lower respiratory diseases and congestive heart failure) compared to the others.

However, LEVY et al. [35] did not find an association between daily indicators of particulate matter and out-of hospital primary cardiac arrest in Seattle, WA, USA with an analysis of effect modification using a case-crossover. The choice of the sudden deaths series of people with no previous history of CVDs was a limitation of the study.

Time series analyses as well as a case-crossover approach were employed by KWON et al. [36] to specifically test the hypothesis that patients with congestive heart failure are more susceptible to air pollution than the general population. This was done by comparing the air pollution related to mortality among the heart failure cohort members with that of the general population in the same area and the same period. The effects attributable to particles with a $50 \%$ cut-off aerodynamic diameter of $10 \mu \mathrm{m}$ (PM10) among the diseased cohort appeared larger than among the general population $(5.8 \%$ versus $1.4 \%$ increase per $\left.42.1 \mu \mathrm{g} \cdot \mathrm{m}^{-3} \mathrm{PM} 10\right)$.

Mechanisms. Several mechanisms, by which clinical conditions may contribute to increase susceptibility in populations, can be hypothesised. 
Acute exacerbations are the most common cause of hospital admissions for COPD. Severe infection-induced exacerbations are associated with a high risk of death up to $40-60 \%$ in the following year. The long-term prognostic factors of the patients are related not only to the respiratory parameters (oxygen tension in arterial blood, carbon dioxide tension in arterial blood; forced vital capacity, FEV1) as well as to the onset of respiratory failure, but also to the cardiac status. Electrocardiogram (ECG) signs of right ventricular hypertrophia (chronic cor pulmonale) and ECG signs of ischaemia were strong predictors of mortality among COPD patients studied in Rome [37]. On the other hand, a depressed left ventricular diastolic performance is a predictive factor for severe arrhythmias during respiratory failure from COPD.

Both myocardial infarction (MI) and ischaemic stroke are the results of sudden and persistent interruption of regional blood flow from thrombosis, spasm, or small-vessel constriction. Patients hospitalised after a MI are extremely frail and at risk of subsequent death; an overall 30-day mortality rate of $\sim 14-15 \%$ and a $1-y r$ mortality rate of $22-24 \%$ have been observed in a population [38]. Moreover, such patients are at a high risk of a subsequent MI or hospital re-admission for angina, cardiac failure, cardiac dysrhythmia, and stroke.

Chronic heart failure is a clinical syndrome mainly due to left-ventricular systolic dysfunction associated with a failure of the heart to pump blood at a rate suitable with the demand. Frequent causes of myocardial failure, which has a relatively high prevalence in the general population, especially among the elderly (5-10\% for those $>65$ yrs) [39] and with mortality reaching $50-75 \%$ within 5 yrs of the diagnosis [40], are coronary ischaemia and valvular diseases. Several factors of the particular susceptibility of patients with heart failure (e.g. infections, hypertension, MI, pulmonary embolism) may precipitate their conditions to death.

Perspectives. The innovative pilot study of PETERS et al. [41] on the role of air pollution among patients with implanted defibrillators has attracted attention to patients with severe heart rhythm disorders. In fact, all conditions (disorders of sinus node function, atrioventricular conduction disturbances (heart blocks), tachycardias) are sensitive to variation of the autonomic tone, a postulated target of the effects of air pollution. Atrial fibrillation affects a large proportion of elderly people $(2.3 \%$ in people $>40 \mathrm{yrs}$ and $5.9 \%$ in those $>65 \mathrm{yrs})$ [42] and is associated with a considerable increase in mortality rates and a four-fold to five-fold increase in the incidence of stroke [43].

Furthermore, there is the attractive hypothesis, according to which oxidants can increase the level of blood coagulability and modify the adhesive properties of red blood cells, thus leading to the increased risk of ischaemic damage in individuals with vulnerable coronary circulation [44].

It is also necessary to mention that breathing pattern (nasal versus oral, especially among COPD patients) may play a role, since there is a more profound deposition of particles in the lower respiratory tract with oral breathing. Patients with COPD, who tend to have oral breathing, seem to have a marked increase in pulmonary particle deposition [45] as well as a reduced clearance [46].

\section{Other factors}

There are other factors, either "endogenous" or "exogenous" (to use the terminology introduced for the study of the natural history of COPD [47]), intervening in susceptibility that may deserve consideration.

Age, for instance, has been well studied and there is a general consensus, as previously shown, that elderly people are more prone than the nonelderly to the effects of pollution $[22,48]$, probably because chronic conditions are more frequent late in life. Among the classical risk factors, tobacco smoking, hypertension, diabetes and high cholesterol have been mentioned [49], but no evidence is available.

Furthermore, intense outdoor physical activity should be evaluated not only because it is associated with oral breathing, but also because it is known to carry an elevated risk of MI and sudden death [50].

Socioeconomic status (SES) appears to be of some interest, especially after the surprising findings emerged from the reanalysis of the large American cohort studies on chronic health effects of particulate matter. KREWSKI et al. [51] found that the relative risk estimates for mortality related to average annual particles with a 50\% cut-off in aerodynamic diameter of $2.5 \mu \mathrm{m}$ (PM2.5) were much higher among those with less than a high school education in comparison with those with post high school education. The reasons for such effect modification are not justified by several confounding factors and remain largely unexplained. One hypothesis is that low SES is associated with higher exposure levels.

\section{Conclusions}

The bulk of the observational studies carried out on the health effects of air pollution have considered large populations in order to detect small relative risks associated with exposure to air pollutants. However, to determine the relevant social, biological, physiological and clinical characteristics that increase the risk of pollution-related health effects requires detailed information at the individual level that are difficult to find. It is also the time to bridge the gap between studies on short-term and long-term effects of air pollution with appropriate epidemiological studies, which include among others: 1) The cohort approach, in which a large data set (including disease registries) are explored to enrol patients with specific characteristics or conditions to be followed in a prospective study. Various outcomes can then be evaluated in relation to the changes (short-term or longterm) of air pollution as long as there are complete ascertainment procedures (e.g. biological parameters, mediations). This approach permits the evaluation of the size of the risk in the "diseased population" in comparison to the general one, as well as the study of further specific characteristics of the subjects within the frail group. The cohort approach is also the first step in order to evaluate survival of patients in relation to air pollution exposure. 2) A new and elegant study design, the case-crossover approach, originally developed to study triggers of MI [52], has recently been applied to air pollution epidemiology [53]. In the study, each subject is their own control during a relevant reference period. The design, in particular the time-stratified approach [15], offers unbiased estimates of the association. The case-crossover approach seems to be particularly suitable to explore the characteristics of the subjects and the susceptibility factors when it is nested within a cohort. The possibility to explore several outcome entities is counterbalanced by loss in statistical power [44]. These designs will allow the role played by sex/"gender" in human susceptibility to be investigated.

In conclusion, it is worth underlying that the finding of a stronger association in a subpopulation with a characteristic that predisposes them to adverse effects of exposure to air pollution will provide insights into the specific role of the pollutant as well as the mechanism of the effects. This finding will also provide a basis for public health interventions. 
Acknowledgements. The authors are indebted to S. Susini for the help in bibliographical research and editing of the manuscript.

\section{References}

1. Utell MJ, Samet JM. Particulate air pollution and health new evidence on an old problem. Am Rev Respir Dis 1993; 147: 1334-1335.

2. Schwartz J. What are people dying of on high air pollution days? Environ Res 1994; 64: 26-35.

3. Bates DV. The effects of air pollution on children. Environ Health Perspect 1995; 130: Suppl. 6, 49-53.

4. Peters JM, Avol E, Gauderman WJ, et al. A study of twelve southern California communities with differing levels and types of air pollution. Am J Respir Crit Care Med 1999; 159: 768-775.

5. Li YF, Gilliland FD, Berhane K, et al. Effects of in utero and environmental tobacco smoke exposure on lung function in boys and girls with and without asthma. Am J Respir Crit Care Med 2000; 162: 2097-2104.

6. Neas LM, Dockery DW, Ware JH, Spengler JD, Speizer FE, Ferris BG Jr. Association of indoor nitrogen dioxide with respiratory symptoms and pulmonary function in children. Am J Epidemiol 1991; 134: 204-219.

7. Chhabra SK, Gupta CK, Chhabra P, Rajpal S. Risk factors for development of bronchial asthma in children in Delhi. Ann Allergy Asthma Immunol 1999; 83: 385-390.

8. Shima M, Nitta Y, Adachi M. Association of outdoor and indoor nitrogen dioxide with pulmonary function in schoolchildren. J Epidemiol 1994; 4: 137-146.

9. Shima M, Adachi M. Effect of outdoor and indoor nitrogen dioxide on respiratory symptoms in schoolchildren. Int $J$ Epidemiol 2000; 29: 862-870.

10. Guo YL, Lin YC, Sung FC, et al. Climate, traffic-related air pollutants, and asthma prevalence in middle-school children in Taiwan. Environ Health Perspect 1999; 107: 1001-1006.

11. Oosterlee A, Drijver M, Lebret E, Brunekreef B. Chronic respiratory symptoms in children and adults living along streets with high traffic density. Occup Environ Med 1996; 53: 241-247.

12. Brunekreef B, Janssen NA, de Hartog J, Harssema H, Knape M, van Vliet P. Air pollution from truck traffic and lung function in children living near motorways. Epidemiology 1997; 8: 298-303.

13. Pershagen G, Rylander E, Norberg S, Eriksson M, Nordvall SL. Air pollution involving nitrogen dioxide exposure and wheezing bronchitis in children. Int J Epidemiol 1995; 24: 1147-1153.

14. Detels R, Tashkin DP, Sayre JW, et al. The UCLA population studies of chronic obstructive respiratory disease. 9. Lung function changes associated with chronic exposure to photochemical oxidants; a cohort study among neversmokers. Chest 1987; 92: 594-603.

15. Jarvis D, Chinn S, Sterne J, Luczynska C, Burney P. The association of respiratory symptoms and lung function with the use of gas for cooking. European Community Respiratory Health Survey. Eur Respir J 1998; 11: 651-658.

16. Dow L, Fowler L, Phelps L, et al. Prevalence of untreated asthma in a population sample of 6000 older adults in Bristol, UK. Thorax 2001; 56: 472-476.

17. Ito A, Takahashi I, Nagata Y, Chiba K, Haraguchi H. The long-term evolutions and the regional characteristics of atmospheric methane concentrations in Nagoya, 1983-1997. Sci Total Environ 2000; 263: 37-45.

18. Schwela D. Air pollution and health in urban areas. Rev Environ Health 2000; 15: 13-42.

19. Wang L, Lubin JH, Zhang SR, et al. Lung cancer and environmental tobacco smoke in a non-industrial area of China. Int J Cancer 2000; 88: 139-145.
20. Health effects of outdoor air pollution. Committee of the Environmental and Occupational Health Assembly of the American Thoracic Society. Am J Respir Crit Care Med 1996; 153: 3-50.

21. Mills PK, Abbey D, Beeson WL, Petersen F. Ambient air pollution and cancer in California Seventh-day Adventists. Arch Environ Health 1991; 46: 271-280.

22. Kauffmann F, Becklake MR. Sex and gender. Eur Respir Mon 2000; 5: 15, 288-304.

23. Pope CA III, Thun MJ, Namboodiri MM, et al. Particulate air pollution as a predictor of mortality in a prospective study of U.S. adults. Am J Respir Crit Care Med 1995; 151: 669-674.

24. Abbey DE, Nishino N, McDonnell WF, et al. Long-term inhalable particles and other air pollutants related to mortality in nonsmokers. Am J Respir Crit Care Med 1999; 159: 373-382.

25. Dockery DW, Pope CA III, Xu X, et al. An association between air pollution and mortality in six cities. $N$ Engl J Med 1993; 329: 1753-1759.

26. Sunyer J, Basagana X. Particles, and not gases, are associated with the risk of death in patients with chronic obstructive pulmonary disease. Int J Epidemiol 2001; 30: 1138-1140.

27. Balzano G, Fuschillo S, Melillo G, Bonini S. Asthma and sex hormones. Allergy 2001; 56: 13-20.

28. Troisi RJ, Speizer FE, Willet MC, Trichopoulos D, Rosner B. Menopause, postmenopausal estrogen preparations and the risk of adult-onset asthma. A prospective cohort study. Am J Respir Crit Care Med 1995; 152: 1183-1188.

29. Perez-Padilla R, Regalado J, Vedal S, et al. Exposure to biomass smoke and chronic airway disease in Mexican women. A case-control study. Am J Respir Crit Care Med 1996; 154: 701-706.

30. Hussain KM, Gould L, Sosler B, Bharathan T, Reddy CV. Clinical science review: current aspects of thrombolytic therapy in women with acute myocardial infarction. Angiology 1996; 47: 23-33.

31. Hanratty B, Lawlor DA, Robinson MB, Sapsford RJ, Greenwood D, Hall A. Sex differences in risk factors, treatment and mortality after acute myocardial infarction: an observational study. J Epidemiol Community Health 2000; 54: 912-916.

32. Sunyer J, Schwartz J, Tobias A, MacFarlane D, Garcia J, Anto JM. Patients with chronic obstructive pulmonary disease are a susceptible population of dying due to urban particles. Am J Epidemiol 2000; 151: 50-56.

33. Zanobetti A, Schwartz J, Dockery DW. Airborne particles are a risk factor for hospital admissions for heart and lung disease. Environ Health Perspect 2000; 108: 1071-1077.

34. Goldberg MS, Burnett RT, Bailar JC III, et al. The association between daily mortality and ambient air particle pollution in Montreal, Quebec. 2. Cause-specific mortality. Environ Res 2001; 86: 26-36.

35. Levy D, Sheppard L, Checkoway H, et al. A case-crossover analysis of particulate matter air pollution and out-ofhospital primary cardiac arrest. Epidemiology 2001; 12: 193199.

36. Kwon HJ, Cho SH, Nyberg F, Pershagen G. Effects of ambient air pollution on daily mortality in a cohort of patients with congestive heart failure. Epidemiology 2001; 12: 413-419.

37. Incalzi RA, Fuso L, De Rosa M, et al. Electrocardiographic signs of chronic cor pulmonale: A negative prognostic finding in chronic obstructive pulmonary disease. Circulation 1999; 99: 1600-1605.

38. Tu JV, Austin P, Naylor CD, Iron K, Zhang H. Acute myocardial infarction outcomes in Ontario. In: Naylor CD, Slaughter PM, eds. Cardiovascular Health and Services in Ontario: An ICES Atlas. Toronto, Institute for Clinical Evaluative Sciences, 1999; pp. 83-110.

39. Davies M, Hobbs F, Davis R, et al. Prevalence of 
left-ventricular systolic dysfunction and heart failure in the Echocardiographic Heart of England Screening study: a population based study. Lancet 2001; 358: 439-444.

40. McKee PA, Castelli WP, McNamara PM, Kannel WB. The natural history of congestive heart failure: the Framingham study. N Engl J Med 1971; 285: 1441-1446.

41. Peters A, Liu E, Verrier RL, et al. Air pollution and incidence of cardiac arrhythmia. Epidemiology 2000; 11: 1117.

42. Feinberg WM, Blackshear JL, Laupacis A, Kronmal R, Hart RG. Prevalence, age distribution and gender of patients with atrial fibrillation. Analysis and implications. Arch Intern Med 1995; 155: 469-473.

43. Gersh BJ, Solomon A. Lone atrial fibrillation: epidemiology and natural history. Am Heart J 1999; 137: 592-595.

44. Seaton A, Soutar A, Crawford V, et al. Particulate air pollution and the blood. Thorax 1999; 54: 1027-1032.

45. Kim CS, Kang TC. Comparative measurement of lung deposition of inhaled fine particles in normal subjects and patients with obstructive airway disease. Am J Respir Crit Care Med 1997; 155: 899-905.

46. Foster WM. Deposition and clearance of inhaled particles. In: Holgate ST, Samet JM, Koren HS, Maynard RL, eds. Air Pollution and Health. San Diego, Academic Press, 1999; pp. 295-324.

47. Orie NGM, Sluiter HJ, De vries K, Tammeling GJ, Witkop J.
The host factors in bronchitis. In: Bronchitis. Ories NGM, Sluiter HJ, eds. Assen, The Netherlands, Royal Van Gorcum, 1961; pp. 43-59.

48. Schwartz J, Dockery DW. Increased mortality in Philadelphia associated with daily air pollution concentrations. Am Rev Respir Dis 1992; 145: 600-604.

49. Prescott GJ, Lee RJ, Cohen GR, et al. Investigation of factors which might indicate susceptibility to particulate air pollution. Occup Environ Med 2000; 57: 53-57.

50. Mittleman MA, Maclure M, Tofler GH, Sherwood JB, Goldberg RJ, Muller JE. Triggering of acute myocardial infarction by heavy physical exertion. Protection against triggering by regular exertion. Determinants of Myocardial Infarction Onset Study Investigators. N Engl J Med 1993; 329: 1677-1683.

51. Krewski D, Burnett RT, Goldberg MS, et al. Reanalysis of the Harvard Six Cities study and the American Cancer Society study of particulate air pollution and mortality. A special report of the Institute's Particle Epidemiology Reanalysis Project. Cambridge, MA, Health Effects Institute, 2000.

52. Maclure M. The case-crossover design: a method for studying transient effects on the risk of acute events. $\mathrm{Am} \mathrm{J}$ Epidemiol 1991; 133: 144-153.

53. Bateson TF, Schwartz J. Control for seasonal variation and time trend in case-crossover studies of acute effects of environmental exposures. Epidemiology 1999; 10: 539-544. 